\title{
Race- and Age-Related Disparities in Cervical Cancer Mortality
}

Stephanie Alimena, MD ${ }^{1,2, *}$; Suvidya Lakshmi Pachigolla, BSc ${ }^{3, *}$; Sarah Feldman, MD, MPH${ }^{1}$; David Yang, MD; Peter F. Orio III, DO, MS ${ }^{4,5}$; Larissa Lee, MD ${ }^{4,5, *}$; and Martin King, MD, PhD $4,5, *$

\begin{abstract}
Background: Although the incidence of cervical cancer among younger Black women is now equivalent to that of White women, it is unknown whether the reduced incidence has affected survival rates among younger Black women. The goal of this study was to assess differences in survival by age and race. Patients and Methods: A retrospective cohort study was performed using the National Cancer Database to analyze women with nonmetastatic cervical cancer diagnosed between 2004 and 2014. Women with unknown survival data and those who died within 3 months of diagnosis were excluded. Multivariable logistic regression models evaluated interactions between age and race (Black vs non-Black) for presentation with stage I disease and receipt of optimal treatment. A multivariable Cox regression model was used to evaluate survival differences by age and race. Results: Of 55,659 women included, 16.4\% were Black. Compared with their non-Black counterparts, fewer Black women presented with stage I disease $(37.8 \%$ vs $47.8 \% ; P<.01)$ and received optimal treatment $(46.2 \%$ vs $58.3 \% ; P<.01)$. Fewer Black women had private insurance if they were aged ,65 years $(39.6 \%$ vs $55.7 \%$; $P<.01)$, but not if they were aged $\geq 65$ years $(11.7 \%$ vs $12.4 \%$; $P 5.43)$. According to multivariable logistic regression, Black women aged $\leq 39$ years were less likely to present with stage I disease, with a significant interaction term between age and race $(P<.01$ for interaction). Disparities in overall survival by race were greatest for Black women aged $\leq 39$ years (adjusted hazard ratio, 1.32; $95 \% \mathrm{Cl}$, $1.20-1.46 ; P<.01)$ but decreased with increasing age interval until no disparity was noted for women aged $\geq 65$ years $(P<.01$ for interaction). Conclusions: Younger Black women with cervical cancer are at risk for presenting with higher-stage disease and having worse overall survival. These findings may be related to insurance-related disparities and inadequate follow-up for abnormal Papanicolaou test results. Younger Black women with cervical cancer may be a particularly vulnerable population.
\end{abstract}

J Natl Compr Canc Netw 2021;19(7):789-795 doi: $10.6004 /$ jnccn. 2020.7665

${ }^{1}$ Division of Gynecologic Oncology, Department of Obstetrics, Gynecology and Reproductive Biology, Brigham and Women's Hospital, Harvard Medical School, Boston, Massachusetts; ${ }^{2}$ Division of Gynecologic Oncology, Vincent Obstetrics and Gynecology, Massachusetts General Hospital, Boston, Massachusetts;

${ }^{3}$ University of Illinois College of Medicine at Peoria, Peoria, Illinois; and

${ }^{4}$ Department of Radiation Oncology, Brigham and Women's Hospital, and

${ }^{5}$ Dana-Farber Cancer Institute, Boston, Massachusetts.

*These authors contributed equally to this manuscript.

See related commentary on page 879 .

\section{Background}

Black women have the highest incidence of and mortality from cervical cancer in the United States. ${ }^{1,2}$ Minority women with cervical cancer are often diagnosed at a higher stage than White women ${ }^{3}$ and are less likely to receive optimal treatment when controlling for confounding factors. ${ }^{4,5}$ Drivers of these racial inequities in care are numerous but include historical differences in Papanicolaou (Pap) screening and follow-up for abnormal Pap test results ${ }^{6,7}$ and social determinants of health, including inadequate insurance coverage, lack of transportation, and financial strain..$^{8,9}$

Little is known about cervical cancer among younger Black women in the United States, who are at higher risk than older Black women of being uninsured or underinsured. ${ }^{10}$ Although the disparity in cervical cancer incidence among younger Black women versus White women has been eliminated since $2005,{ }^{11}$ it is not clear whether this has translated into improved survival for younger Black women. The goal of this study was to assess differences in receipt of optimal treatment for cervical cancer and survival by age and race.

\section{Patients and Methods}

We performed a retrospective cohort study of women who were diagnosed with nonmetastatic cervical cancer (stage IA-IVA) and received treatment at a National Cancer Database (NCDB) reporting facility between January 1, 2004, and December 31, 2014 (see supplemental eFigure 1, available with this article at JNCCN.org). The NCDB collects data from approximately 1,500 cancer programs accredited by the American College of Surgeons' Commission on Cancer. Approximately $70 \%$ of all US patients diagnosed with cancer are recorded in the NCDB, which is a hospital-based registry. ${ }^{12}$

Women with unknown survival data and those who died within 3 months of diagnosis were excluded, because these women may have died of treatment-related complications rather than cervical cancer (supplemental

See JNCCN.org for supplemental online content. 
eFigure 1). Histology was defined as squamous cell histology and nonsquamous cell histology. Squamous cell histology was defined as codes $8070,8071,8072$, 8073, 8074, 8075, and 8076, which are all the existing codes for squamous cell histology according to the ICD-O-3. Stage is entered into the NCDB using the AJCC Cancer Staging Manual edition that was in use at time of diagnosis. Race was defined as Black or nonBlack race, given previous data suggesting similar survival rates for Hispanic and Asian patients compared with White patients. ${ }^{13,14}$ Optimal treatment was defined as receipt of surgery or radiation therapy (RT), including brachytherapy for patients with stage IA-IB1 or IIA1 disease. For stage IB2, IIA2, or IIB-IVA or nodepositive disease, optimal treatment was defined as receipt of RT and chemotherapy.

Statistical analyses were performed using $\mathrm{R}$ version 3.5.0 (R Foundation for Statistical Computing). A $P$ value of .05 was set as the threshold for statistical significance. Multivariable logistic regression models were used to evaluate interactions between age and race (Black vs non-Black) for presentation with stage I disease, receipt of optimal treatment, and odds of having private insurance. The following baseline variables were included in the model: age ( $\leq 39,40-49,50-64$, or $\geq 65$ years), race per age interval (Black or non-Black), stage (I, II, III, or IVA), year of diagnosis (2004-2009 or 2010-2014), histology (squamous or nonsquamous), Charlson-Deyo comorbidity score $(0,1$, or $\geq 2$ ), insurance status (private, government, noninsured, or unknown), and facility volume (high or low). High-volume facilities were defined as hospitals that are ranked $\geq 90$ th percentile for patient volume, whereas lowvolume facilities were defined as those ranked $<90$ th percentile. Interaction $P$ values were calculated to determine the relationship between race per age interval and odds of having stage I disease, odds of receiving optimal treatment, and odds of having private insurance.

To evaluate the interaction between age and race on survival, a multivariable Cox regression model was used, controlling for age, Black race per age interval, stage, optimal treatment, year of diagnosis, histology, CharlsonDeyo comorbidity score, insurance status, and facility volume. Overall survival (OS) was determined for the study population overall, for those who received optimal treatment, and for those who had nonoptimal treatment. Interaction $P$ values were calculated to determine the relationship between race per age interval and OS.

In addition, treatment disparities were further assessed by determining rates of adverse pathology (eg, positive margins or pathologic nodal involvement) among Black and non-Black women who received surgery to determine if rates of postoperative RT differed by race. Completion of RT within 8 weeks was also compared by race using chi-square analysis because prior data showed worse

\begin{tabular}{|c|c|c|c|}
\hline Clinical Factor & $\begin{array}{c}\text { Non-Black } \\
\text { n (\%) }\end{array}$ & $\begin{array}{l}\text { Black } \\
\text { n (\%) }\end{array}$ & $P$ Value \\
\hline Total, N & 46,506 & 9,153 & \\
\hline Age, y & & & $<.01$ \\
\hline$\leq 39$ & $11,486(24.70 \%)$ & $1,960(21.41 \%)$ & \\
\hline $40-49$ & $12,293(26.43 \%)$ & $2,308(25.22 \%)$ & \\
\hline $50-64$ & 14,189 (30.51\%) & 2,959 (32.33\%) & \\
\hline$\geq 65$ & $8,538(18.36 \%)$ & $1,926(21.04 \%)$ & \\
\hline Cancer stage & & & $<.01$ \\
\hline 1 & 22,235 (47.81\%) & $3,458(37.78 \%)$ & \\
\hline II & $10,706(23.02 \%)$ & $2,282(24.93 \%)$ & \\
\hline III & $12,115(26.05 \%)$ & 3,079 (33.64\%) & \\
\hline IVA & $1,450(3.12 \%)$ & 334 (3.65\%) & \\
\hline Year of diagnosis & & & $<.01$ \\
\hline 2004-2009 & $18,603(40.00 \%)$ & $3,974(43.42 \%)$ & \\
\hline 2010-2014 & $27,903(60.00 \%)$ & $5,179(56.58 \%)$ & \\
\hline Histology & & & $<.01$ \\
\hline Squamous & 24,978 (53.71\%) & $5,873(64.16 \%)$ & \\
\hline Nonsquamous & 21,528 (46.29\%) & $3,280(35.84 \%)$ & \\
\hline \multicolumn{2}{|c|}{ Charlson-Deyo comorbidity score } & & $<.01$ \\
\hline 0 & $40,315(86.69 \%)$ & $7,420(81.07 \%)$ & \\
\hline 1 & $5,000(10.75 \%)$ & 1,271 (13.89\%) & \\
\hline$\geq 2$ & 1,191 (2.56\%) & 462 (5.05\%) & \\
\hline Insurance & & & $<.01$ \\
\hline Private & 22,198 (47.73\%) & 3,087 (33.73\%) & \\
\hline Government & $18,798(40.42 \%)$ & $4,828(52.75 \%)$ & \\
\hline None & $4,483(9.64 \%)$ & $990(10.82 \%)$ & \\
\hline Unknown & $1,027(2.21 \%)$ & $248(2.71 \%)$ & \\
\hline Facility volume ${ }^{a}$ & & & $<.01$ \\
\hline High & $20,379(43.82 \%)$ & $4,616(50.43 \%)$ & \\
\hline Low & $26,127(56.18 \%)$ & 4,537 (49.57\%) & \\
\hline Treatment type & & & $<.01$ \\
\hline Surgery & 20,301 (43.65\%) & 2,739 (29.92\%) & \\
\hline Radiotherapy & 23,905 (51.40\%) & $5,792(63.28 \%)$ & \\
\hline None & $2,300(4.95 \%)$ & $622(6.80 \%)$ & \\
\hline Optimal treatment & & & $<.01$ \\
\hline Yes & $27,117(58.31 \%)$ & 4,224 (46.15\%) & \\
\hline No & 19,389 (41.69\%) & 4,929 (53.85\%) & \\
\hline
\end{tabular}

aHigh-volume facilities were defined as those facilities that are ranked $\geq 90$ th percentile for patient volume, and low-volume facilities were considered those ranked $<90$ th percentile.

outcomes, including diminished locoregional control and possibly worse OS when RT is completed in $>8$ weeks. ${ }^{15-18}$ NCCN Clinical Practice Guidelines in Oncology (NCCN Guidelines) for Cervical Cancer also recommend that RT be completed within 8 weeks based on these data. ${ }^{19}$ 


\section{Results}

A total of 105,766 women with cervical cancer were diagnosed between 2004 and 2014 and recorded in the NCDB. We excluded 42,185 patients with metastatic disease and 7,922 with unknown survival data or who died within 3 months of diagnosis (supplemental eFigure 1). The final cohort consisted of 55,659 women, 9,153 (16.4\%) of whom were Black. Compared with their non-Black counterparts, fewer Black women presented with stage I disease (37.8\% vs $47.8 \%$, respectively; $P<.01$ ) and received optimal treatment $(46.2 \%$ vs $58.3 \% ; P<.01)$ (Table 1 ). Fewer Black women had private insurance if aged $<65$ years $(39.6 \%$ vs $55.7 \% ; P<.01)$ but not if aged $\geq 65$ years ( $11.7 \%$ vs $12.4 \% ; P=.43$ ). Figure 1 shows differences in private insurance, stage I disease, and optimal treatment among Black versus non-Black patients by age.

Multivariable logistic regression (Table 2) revealed that the interaction between age and race was significant for presentation with stage I disease, with Black women aged $\leq 39$ years being less likely to present with stage I disease (adjusted odds ratio, 0.65; $P<.01)$. The interaction between age and race was not significant for receipt of optimal treatment, although Black women of all ages were less likely to receive optimal treatment.

Multivariable Cox regression revealed that disparities in OS by race were greatest for Black women aged $\leq 39$ years (adjusted hazard ratio [aHR], 1.32; 95\% CI, $1.20-1.46$; $P<.01)$ but decreased with increasing age interval until no disparity was noted for women aged $\geq 65$ years (Table 3 ). The interaction between age and race was significant $(P<.01$ for interaction) (Figure 2$)$. When the analysis was restricted to women who received optimal treatment, this interaction was no longer significant $(P=.61)$. However, there remained a nonsignificant survival disparity for women aged $\leq 39$ years who received optimal treatment (aHR, 1.18; 95\% CI, $1.00-1.39 ; P=.06)$.
Further analysis of treatment disparities revealed similar rates of adverse pathology (eg, positive margins or pathologic nodal involvement) between Black and non-Black women who received optimal treatment with surgery ( $13.4 \%$ vs $13.6 \% ; P=.81$ ). However, Black women were less likely to receive postoperative RT for adverse pathology $(51.3 \%$ vs $59.6 \% ; P<.01)$. Furthermore, Black women who received optimal treatment with RT were less likely to complete treatment in $\leq 8$ weeks $(45.2 \%$ vs 50.0\%; $P<.01)$.

\section{Discussion}

Our findings showed significant differences in optimal treatment and survival by race and age. Younger Black women were less likely to present with stage I disease, and there was a persistent survival disparity in younger Black women in the setting of treatment disparities. Even when they received optimal treatment according to NCCN Guidelines, younger Black women were more likely to experience delays in the receipt of RT and less likely to even undergo RT if adverse pathology was detected at the time of surgery. This is consistent with prior work suggesting that treatment-related disparities may mediate survival differences in Black women with cervical cancer. ${ }^{4,20}$

Younger Black women in our study were less likely than younger non-Black women to present with stage I disease. This suggests that there remain inadequacies in follow-up for abnormal Pap test results among younger Black women in particular, leading to diagnosis at later stages. Prior studies have shown that minority women have lower rates of follow-up for abnormal Pap test results and lower rates of colposcopy. ${ }^{7,21}$ Younger Black women were also less likely than older Black women to have private insurance in our study. Therefore, it is possible that insurance status may also be contributing to lack of abnormal Pap test follow-up in underinsured younger Black women.
A

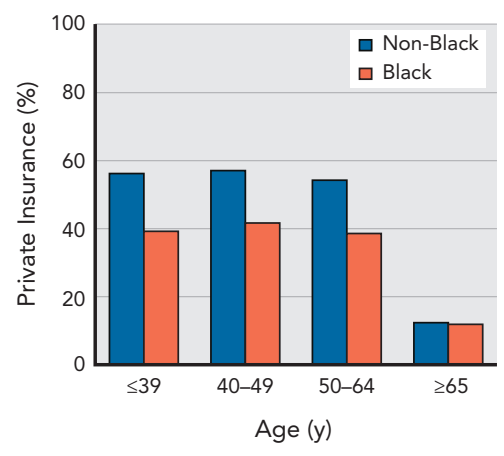

B

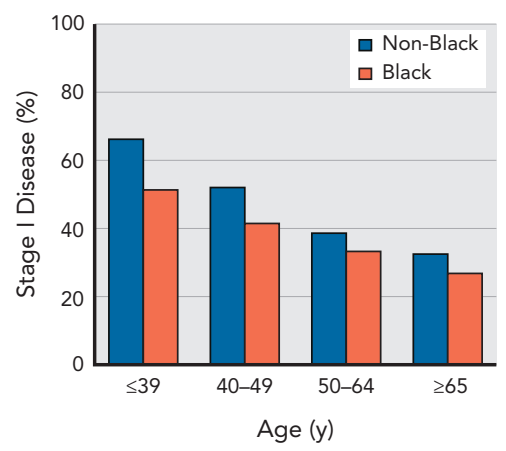

C

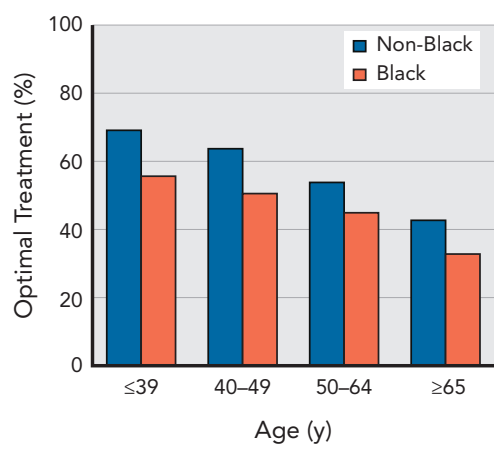

Figure 1. Differences in (A) private insurance, (B) stage I disease, and (C) optimal treatment among Black versus non-Black patients by age. 
Table 2. Odds of Stage I Disease, Optimal Treatment, and Private Insurance by Race and Age Interval

\begin{tabular}{|c|c|c|c|c|c|c|}
\hline \multirow[b]{2}{*}{ Clinical Factor } & \multicolumn{2}{|c|}{ Stage I Disease } & \multicolumn{2}{|c|}{ Optimal Treatment } & \multicolumn{2}{|c|}{ Private Insurance } \\
\hline & aOR $(95 \% \mathrm{Cl})$ & $P$ Value & aOR $(95 \% \mathrm{Cl})$ & $P$ Value & aOR $(95 \% \mathrm{Cl})$ & $P$ Value \\
\hline \multicolumn{7}{|l|}{ Age, y } \\
\hline$\leq 39$ & Ref & & Ref & & Ref & \\
\hline $40-49$ & $0.55(0.52-0.58)$ & $<.01$ & $1.07(1.01-1.14)$ & .02 & $1.14(1.09-1.21)$ & $<.01$ \\
\hline $50-64$ & $0.32(0.30-0.33)$ & $<.01$ & $0.90(0.85-0.95)$ & $<.01$ & $1.14(1.09-1.21)$ & $<.01$ \\
\hline$\geq 65$ & $0.30(0.28-0.32)$ & $<.01$ & $0.63(0.59-0.68)$ & $<.01$ & $0.13(0.12-0.14)$ & $<.01$ \\
\hline \multicolumn{7}{|c|}{ Effect of Black race per age interval, y } \\
\hline$\leq 39$ & $0.65(0.59-0.72)$ & $<.01$ & $0.73(0.65-0.81)$ & $<.01$ & $0.58(0.52-0.64)$ & $<.01$ \\
\hline $40-49$ & $0.79(0.71-0.86)$ & $<.01$ & $0.68(0.61-0.75)$ & $<.01$ & $0.62(0.56-0.68)$ & $<.01$ \\
\hline $50-64$ & $0.91(0.83-0.99)$ & .03 & $0.76(0.69-0.83)$ & $<.01$ & $0.57(0.53-0.62)$ & $<.01$ \\
\hline$\geq 65$ & $0.78(0.70-0.88)$ & $<.01$ & $0.67(0.60-0.76)$ & $<.01$ & $1.02(0.88-1.19)$ & .77 \\
\hline \multicolumn{7}{|l|}{ Cancer stage } \\
\hline I & - & - & Ref & & Ref & \\
\hline ॥ & - & - & $0.16(0.15-0.17)$ & $<.01$ & $0.59(0.57-0.62)$ & $<.01$ \\
\hline III & - & - & $0.10(0.09-0.10)$ & $<.01$ & $0.54(0.52-0.57)$ & $<.01$ \\
\hline IVA & - & - & $0.05(0.04-0.06)$ & $<.01$ & $0.43(0.39-0.48)$ & $<.01$ \\
\hline \multicolumn{7}{|l|}{ Year of diagnosis } \\
\hline 2004-2009 & Ref & & Ref & & Ref & \\
\hline $2010-2014$ & $2.17(2.09-2.26)$ & $<.01$ & $1.25(1.20-1.30)$ & $<.01$ & $0.89(0.86-0.92)$ & $<.01$ \\
\hline \multicolumn{7}{|l|}{ Histology } \\
\hline Squamous & Ref & & Ref & & Ref & \\
\hline Nonsquamous & $2.06(1.99-2.14)$ & $<.01$ & $1.13(1.09-1.18)$ & $<.01$ & $1.39(1.34-1.44)$ & $<.01$ \\
\hline \multicolumn{7}{|c|}{ Charlson-Deyo comorbidity score } \\
\hline 0 & Ref & & Ref & & Ref & \\
\hline 1 & $1.13(1.06-1.19)$ & $<.01$ & $1.04(0.98-1.11)$ & .22 & $0.76(0.71-0.80)$ & $<.01$ \\
\hline$\geq 2$ & $1.14(1.03-1.27)$ & .02 & $0.66(0.58-0.74)$ & $<.01$ & $0.44(0.39-0.50)$ & $<.01$ \\
\hline \multicolumn{7}{|l|}{ Insurance } \\
\hline Private & Ref & & Ref & & - & - \\
\hline Government & $0.59(0.56-0.61)$ & $<.01$ & $0.82(0.78-0.86)$ & $<.01$ & - & - \\
\hline None & $0.45(0.43-0.48)$ & $<.01$ & $0.66(0.62-0.71)$ & $<.01$ & - & - \\
\hline Unknown & $0.65(0.57-0.73)$ & $<.01$ & $0.42(0.37-0.49)$ & $<.01$ & - & - \\
\hline \multicolumn{7}{|l|}{ Facility volume ${ }^{a}$} \\
\hline High & Ref & & Ref & & Ref & \\
\hline Low & $1.06(1.02-1.10)$ & $<.01$ & $0.76(0.73-0.79)$ & $<.01$ & $1.35(1.30-1.40)$ & $<.01$ \\
\hline Intercept & $1.09(1.03-1.15)$ & $<.01$ & $6.00(5.60-6.43)$ & $<.01$ & $1.25(1.18-1.32)$ & $<.01$ \\
\hline Interaction $P$ value & $<.01$ & & .36 & & .01 & \\
\hline
\end{tabular}

Abbreviation: aOR, adjusted odds ratio.

aHigh-volume facilities were defined as those facilities that are ranked $\geq 90$ th percentile for patient volume, and low-volume facilities were considered those ranked $<90$ th percentile.

We also found that disparities in OS by race were greatest for Black women aged $\leq 39$ years and that disparities diminished with increasing age, until no disparity was noted for Black women aged $\geq 65$ years. When restricted to women who received optimal treatment, the interaction between race and age was no longer significant despite maintaining a large sample size in this analysis $(n=31,341)$. Therefore, our study also highlights the importance of access to quality treatment, because disparities in OS by race and age were noted 
Table 3. Overall Survival by Optimal and Nonoptimal Treatment

\begin{tabular}{|c|c|c|c|c|c|c|}
\hline \multirow[b]{2}{*}{ Clinical Factor } & \multicolumn{2}{|c|}{$\begin{array}{c}\text { All } \\
(\mathrm{N}=\mathbf{5 5 , 6 5 9 )}\end{array}$} & \multicolumn{2}{|c|}{$\begin{array}{c}\text { Optimal Treatment } \\
(n=31,341)\end{array}$} & \multicolumn{2}{|c|}{$\begin{array}{c}\text { Nonoptimal Treatment } \\
(n=24,318)\end{array}$} \\
\hline & aHR & $P$ Value & aHR & $P$ Value & aHR & $P$ Value \\
\hline \multicolumn{7}{|l|}{ Age, y } \\
\hline$\leq 39$ & Ref & & Ref & & Ref & \\
\hline $40-49$ & $1.15(1.09-1.22)$ & $<.01$ & $1.17(1.07-1.28)$ & $<.01$ & $1.14(1.06-1.23)$ & $<.01$ \\
\hline $50-64$ & $1.33(1.26-1.41)$ & $<.01$ & $1.40(1.29-1.53)$ & $<.01$ & $1.26(1.18-1.36)$ & $<.01$ \\
\hline$\geq 65$ & $2.03(1.92-2.15)$ & $<.01$ & $2.14(1.95-2.34)$ & $<.01$ & $1.92(1.78-2.06)$ & $<.01$ \\
\hline \multicolumn{7}{|c|}{ Effect of Black race per age interval, $y$} \\
\hline$\leq 39$ & $1.32(1.20-1.46)$ & $<.01$ & $1.18(1.00-1.39)$ & .06 & $1.35(1.20-1.52)$ & $<.01$ \\
\hline $40-49$ & $1.20(1.10-1.30)$ & $<.01$ & $1.10(0.95-1.27)$ & .21 & $1.21(1.10-1.34)$ & $<.01$ \\
\hline $50-64$ & $1.14(1.06-1.21)$ & $<.01$ & $1.07(0.95-1.20)$ & .27 & $1.16(1.07-1.25)$ & $<.01$ \\
\hline$\geq 65$ & $1.02(0.95-1.09)$ & .66 & $1.02(0.88-1.17)$ & .83 & $1.03(0.95-1.11)$ & .53 \\
\hline \multicolumn{7}{|l|}{ Cancer stage } \\
\hline 1 & Ref & & Ref & & Ref & \\
\hline II & $1.90(1.81-1.99)$ & $<.01$ & $2.44(2.28-2.61)$ & $<.01$ & $1.28(1.20-1.37)$ & $<.01$ \\
\hline III & $3.29(3.14-3.44)$ & $<.01$ & $4.32(4.05-4.61)$ & $<.01$ & $2.22(2.09-2.36)$ & $<.01$ \\
\hline IVA & $5.16(4.81-5.54)$ & $<.01$ & $5.80(4.91-6.85)$ & $<.01$ & $3.63(3.34-3.95)$ & $<.01$ \\
\hline \multicolumn{7}{|l|}{ Optimal treatment } \\
\hline No & Ref & & - & - & - & - \\
\hline Yes & $0.64(0.62-0.66)$ & $<.01$ & - & - & - & - \\
\hline \multicolumn{7}{|l|}{ Year of diagnosis } \\
\hline 2004-2009 & Ref & & Ref & & Ref & \\
\hline 2010-2014 & $0.81(0.78-0.84)$ & $<.01$ & $0.85(0.81-0.90)$ & $<.01$ & $0.80(0.77-0.83)$ & $<.01$ \\
\hline \multicolumn{7}{|l|}{ Histology } \\
\hline Squamous & Ref & & Ref & & Ref & \\
\hline Nonsquamous & $1.09(1.05-1.12)$ & $<.01$ & $1.07(1.01-1.12)$ & .02 & $1.11(1.07-1.16)$ & $<.01$ \\
\hline \multicolumn{7}{|c|}{ Charlson-Deyo comorbidity score } \\
\hline 0 & Ref & & Ref & & Ref & \\
\hline 1 & $1.27(1.22-1.33)$ & $<.01$ & $1.29(1.20-1.39)$ & $<.01$ & $1.26(1.20-1.33)$ & $<.01$ \\
\hline$\geq 2$ & $1.71(1.59-1.83)$ & $<.01$ & $1.83(1.60-2.09)$ & $<.01$ & $1.65(1.52-1.80)$ & $<.01$ \\
\hline \multicolumn{7}{|l|}{ Insurance } \\
\hline Private & Ref & & Ref & & Ref & \\
\hline Government & $1.34(1.30-1.39)$ & $<.01$ & $1.38(1.30-1.46)$ & $<.01$ & $1.30(1.24-1.37)$ & $<.01$ \\
\hline None & $1.20(1.13-1.26)$ & $<.01$ & $1.19(1.08-1.31)$ & $<.01$ & $1.17(1.09-1.25)$ & $<.01$ \\
\hline Unknown & $1.05(0.95-1.17)$ & .32 & $1.11(0.90-1.36)$ & .34 & $1.02(0.90-1.14)$ & .80 \\
\hline \multicolumn{7}{|l|}{ Facility volume ${ }^{a}$} \\
\hline High & Ref & & Ref & & Ref & \\
\hline Low & $1.07(1.04-1.11)$ & $<.01$ & $1.11(1.05-1.16)$ & $<.01$ & $1.06(1.02-1.10)$ & $<.01$ \\
\hline Interaction $P$ value & $<.01$ & & .61 & & $<.01$ & \\
\hline
\end{tabular}

Abbreviation: aHR, adjusted hazard ratio.

aHigh-volume facilities were defined as those facilities that are ranked $\geq 90$ th percentile for patient volume, and low-volume facilities were considered those ranked $<90$ th percentile. 
among those who did not receive optimal treatment. We also found that Black women were less likely to receive postoperative RT for adverse pathology and that those who did receive RT were less likely to complete treatment in $\leq 8$ weeks. Multiple factors contribute to the ability of patients to receive optimal treatment, including distance to treatment centers, hospital volume of those centers, and patient finances, insurance status, comorbidities, education, and health literacy. ${ }^{4,9,20,22-26}$ Minority women may have more barriers to receiving treatment, including difficulty in assuring transportation, diminished ability to take time away from family or work responsibilities, financial strain, and poor understanding of the importance or significance of treatments.

Because of the retrospective nature of our study, we were unable to determine the exact cause of these treatment-related disparities; however, it is interesting that younger Black women were less likely to have private insurance and had worse OS in our study. We also found that both women with government insurance and uninsured women were at higher risk of mortality. Insurance-related disparities were an important predictor of outcomes among minority women in prior studies. ${ }^{20}$ In the United States, Black women are more likely than women of other races to be unemployed or to hold low-wage jobs that do not provide health benefits. ${ }^{27}$ Therefore, $>3.3$ million Black women (or 1 in 4 nationally) are covered by Medicaid. On the one hand, younger, underinsured Black women, especially those who live in states that did not expand Medicaid with the Affordable Care Act, may encounter delays in obtaining insurance coverage and ultimately cancer screening and treatment. ${ }^{28}$ On the other hand, older Black women aged $\geq 65$ years may not encounter such delays, because many are already enrolled in Medicare. Health insurance coverage among Black women varies in the United States by age: although $98.4 \%$ of Black women aged $\geq 65$ years are insured, only $87.7 \%$ aged 18 to 64 years have coverage. ${ }^{29}$ In addition, in many states, emergency insurance coverage can be enacted when cervical cancer is diagnosed, but significant delays in receiving coverage may be encountered, with reports of delays of up to 4 months for some patients. ${ }^{26}$ Furthermore, the complexity of signing up for insurance plans in the United States may impact the ability of minority women to receive timely care. Signing up for emergency coverage after a cancer diagnosis may explain why uninsured women and women with government insurance had similar poor survival outcomes in our study, given that the NCDB does not capture data regarding who received emergency coverage for treatment. Treatment delays in minority women have been associated with increased mortality in prior

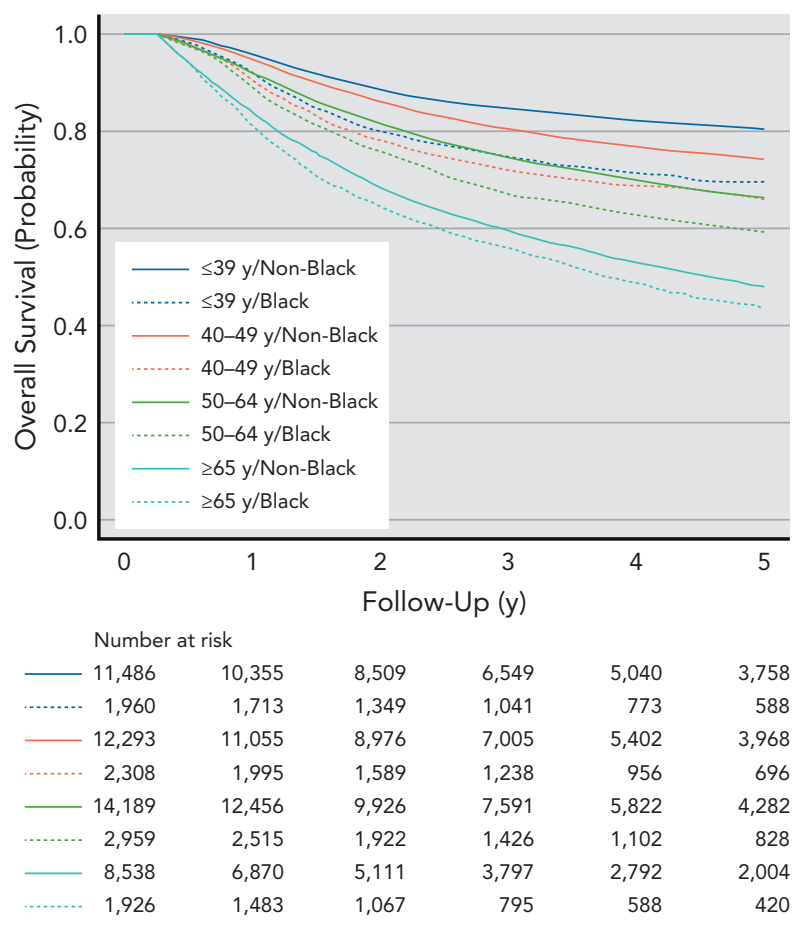

Figure 2. Overall survival by race and age interval.

studies. ${ }^{30}$ Thus, lack of insurance and/or delays in receipt of emergency insurance coverage may also contribute to the survival disparities noted in this study among younger Black women.

\section{Conclusions}

This study suggests that younger Black women are at higher risk of presentation with later-stage cervical cancer, suboptimal treatment of cervical cancer, and increased mortality compared with their non-Black counterparts.Multiple factors may contribute to these findings, including inadequate healthcare coverage among younger Black women, who may be a particularly vulnerable population. Improving follow-up for abnormal Pap test results and access to universal health insurance may help reduce treatment and survival disparities in this at-risk population.

\section{Acknowledgments}

The authors acknowledge Brandon Mahal, MD, in the Department of Radiation Oncology at Brigham and Women's Hospital, for his contributions in reviewing the manuscript. No compensation was received for his role.

Submitted June 11, 2020; final revision received September 28, 2020; accepted for publication September 29, 2020. Published online April 1, 2021.

Author contributions: Study concept: Alimena, Pachigolla, Feldman, Lee, King. Data curation: Yang, Orio, Lee, King. Formal analysis: Lee, King. Investigation: Alimena, Pachigolla, Lee, King. Methodology: Lee, King. Writing - original draft: Alimena, Pachigolla. Writing - review and editing: All authors 
Disclosures: The authors have disclosed that they have not received any financial considerations from any person or organization to support the preparation, analysis, results, or discussion of this article
Correspondence: Stephanie Alimena, MD, Division of Gynecologic Oncology, Department of Obstetrics, Gynecology and Reproductive Biology, Brigham and Women's Hospital, 75 Francis Street, Boston, MA 02115.

Email: salimena@partners.org

\section{References}

1. Siegel RL, Miller KD, Jemal A. Cancer statistics, 2018. CA Cancer J Clin 2018;68:7-30

2. Benard VB, Watson $M$, Saraiya $M$, et al. Cervical cancer survival in the United States by race and stage (2001-2009): findings from the CONCORD-2 study. Cancer 2017;123(Suppl 24):5119-5137.

3. DeSantis CE, Miller KD, Goding Sauer A, et al. Cancer statistics for African Americans, 2019. CA Cancer J Clin 2019;69:211-233.

4. Alimena S, Yang DD, Melamed A, et al. Racial disparities in brachytherapy administration and survival in women with locally advanced cervical cancer. Gynecol Oncol 2019;154:595-601.

5. del Carmen MG, Montz FJ, Bristow RE, et al. Ethnic differences in patterns of care of stage $1 \mathrm{~A}(1)$ and stage $1 \mathrm{~A}(2)$ cervical cancer: a SEER database study. Gynecol Oncol 1999;75:113-117.

6. Garner El. Cervical cancer: disparities in screening, treatment, and survival. Cancer Epidemiol Biomarkers Prev 2003;12:242s-247s.

7. Benard VB, Lawson HW, Eheman CR, et al. Adherence to guidelines for follow-up of low-grade cytologic abnormalities among medically underserved women. Obstet Gynecol 2005;105:1323-1328.

8. Chatterjee S, Gupta D, Caputo TA, et al. Disparities in gynecological malignancies. Front Oncol 2016;6:36.

9. Uppal S, Chapman C, Spencer RJ, et al. Association of hospital volume with racial and ethnic disparities in locally advanced cervical cancer treatment. Obstet Gynecol 2017;129:295-304.

10. National Cancer Institute: Cancer Trends Progress Report.Cervical cancer screening. Accessed September 28, 2020. Available at: https://progressreport.cancer.gov/detection/cervical_cancer

11. Simard EP, Naishadham D, Saslow D, et al. Age-specific trends in blackwhite disparities in cervical cancer incidence in the United States: 1975 2009. Gynecol Oncol 2012;127:611-615.

12. Bilimoria KY, Stewart AK, Winchester DP, et al. The National Cancer Data Base: a powerful initiative to improve cancer care in the United States. Ann Surg Oncol 2008;15:683-690.

13. Nghiem VT, Davies KR, Chan W, et al. Disparities in cervical cancer survival among Asian-American women. Ann Epidemiol 2016;26:28-35.

14. Patel DA, Barnholtz-Sloan JS, Patel MK, et al. A population-based study of racial and ethnic differences in survival among women with invasive cervical cancer: analysis of Surveillance, Epidemiology, and End Results data. Gynecol Oncol 2005;97:550-558.

15. Mazeron R, Castelnau-Marchand P, Dumas I, et al. Impact of treatment time and dose escalation on local control in locally advanced cervical cancer treated by chemoradiation and image-guided pulsed-dose rate adaptive brachytherapy. Radiother Oncol 2015;114:257-263.

16. Song S, Rudra S, Hasselle MD, et al. The effect of treatment time in locally advanced cervical cancer in the era of concurrent chemoradiotherapy. Cancer 2013;119:325-331.
17. Tanderup K, Fokdal LU, Sturdza A, et al. Effect of tumor dose, volume and overall treatment time on local control after radiochemotherapy including MRI guided brachytherapy of locally advanced cervical cancer. Radiother Oncol 2016;120:441-446.

18. Petereit DG, Sarkaria JN, Chappell R, et al. The adverse effect of treatment prolongation in cervical carcinoma. Int J Radiat Oncol Biol Phys 1995;32:1301-1307.

19. Abu-Rustum NR, Yashar CM, Bean S, et al. NCCN Clinical Practice Guidelines in Oncology: Cervical Cancer. Version 4.2019. Accessed September 28, 2020. To view the most recent version, visit NCCN.org

20. Markt SC, Tang T, Cronin AM, et al. Insurance status and cancer treatment mediate the association between race/ethnicity and cervical cancer survival. PLoS One 2018;13:e0193047.

21. Fish LJ, Moorman PG, Wordlaw-Stintson L, et al. Factors associated with adherence to follow-up colposcopy. Am J Health Educ 2013;44 293-298.

22. Spees LP, Brewster WR, Varia MA, et al. Examining urban and rural differences in how distance to care influences the initiation and completion of treatment among insured cervical cancer patients. Cancer Epidemiol Biomarkers Prev 2019;28:882-889.

23. Bouberhan $S$, Shea $M$, Kennedy A, et al. Financial toxicity in gynecologic oncology. Gynecol Oncol 2019;154:8-12.

24. Sudore RL, Yaffe K, Satterfield S, et al. Limited literacy and mortality in the elderly: the Health, Aging, and Body Composition study. J Gen Intern Med 2006;21:806-812.

25. Ell K, Vourlekis B, Xie B, et al. Cancer treatment adherence among low-income women with breast or gynecologic cancer: a randomized controlled trial of patient navigation. Cancer 2009;115: 4606-4615

26. Westin SN, Bustillos D, Gano JB, et al. Social factors affecting treatment of cervical cancer: ethical issues and policy implications. Obstet Gynecol 2008;111:747-751.

27. US Bureau of Labor Statistics. Labor force characteristics by race and ethnicity, 2018. Accessed June 9, 2020. Available at: https://www.bls.gov/ opub/reports/race-and-ethnicity/2018/home.htm

28. Sabik LM, Tarazi WW, Bradley CJ. State Medicaid expansion decisions and disparities in women's cancer screening. Am J Prev Med 2015;48: 98-103.

29. United States Census Bureau. Table 14. Health insurance status by sex and age, for black alone and white alone, not Hispanic: 2019. Accessed June 9, 2020. Available at: https://www.census.gov/data/tables/2019/ demo/race/ppl-ba19.html

30. Ramey SJ, Asher D, Kwon D, et al. Delays in definitive cervical cancer treatment: an analysis of disparities and overall survival impact. Gynecol Oncol 2018;149:53-62.

\section{See JNCCN.org for supplemental online content.}




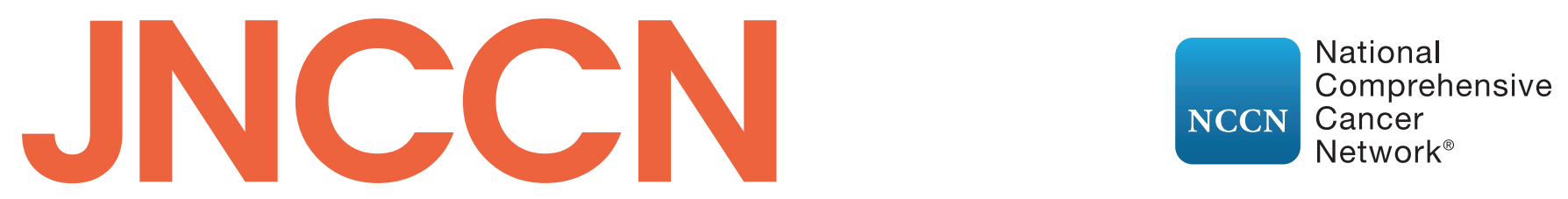

Supplemental online content for:

\section{Race- and Age-Related Disparities in Cervical Cancer Mortality}

Stephanie Alimena, MD; Suvidya Lakshmi Pachigolla, BSc; Sarah Feldman, MD, MPH; David Yang, MD; Peter F. Orio III, DO, MS; Larissa Lee, MD; and Martin King, MD, PhD

J Natl Compr Canc Netw 2021;19(7):789-795

eFigure 1: Inclusion and Exclusion Criteria 


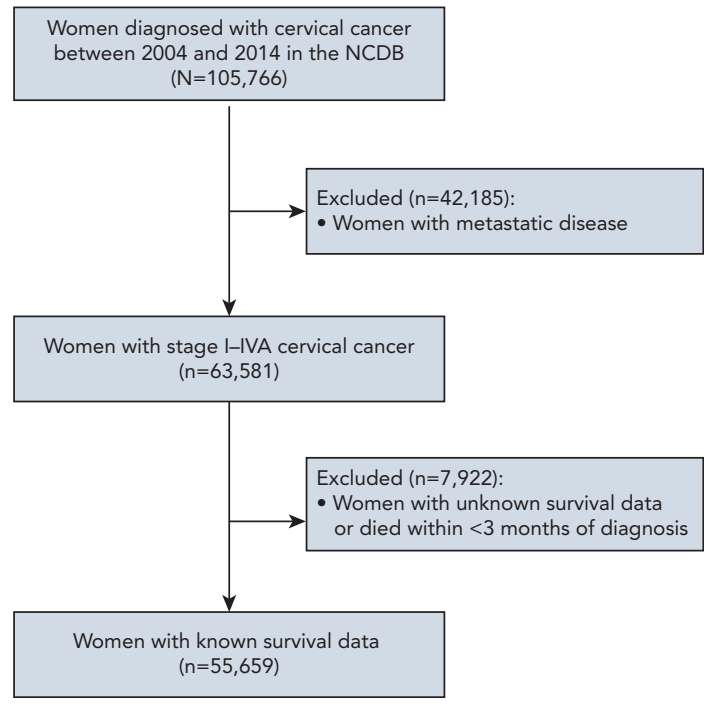

eFigure 1. Inclusion and exclusion criteria. Abbreviation: NCDB, National Cancer Database. 